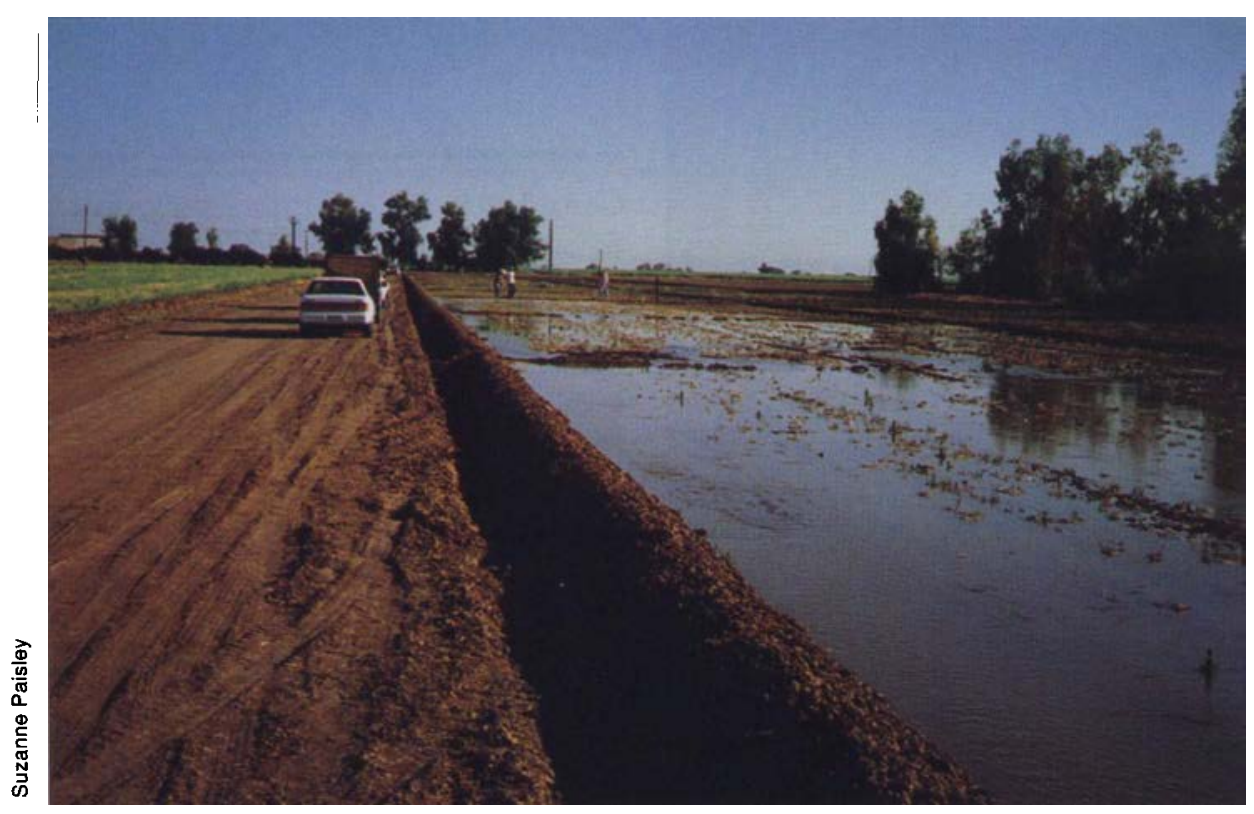

\section{Continuous ponding and shallow aquifer pumping leaches salts in clay soils}

Mark E. Grismer $\quad \square \quad$ Khaled M. Bali
With continuous ponding for 1 month, scientists were able to leach salts deeper in the heavy clay soil at the UC Desert Research \& Extension Center.

conducted by Robinson, Luthin and others in the previous three decades. We have found that a shallow artesian sand aquifer underlying the clay soil contributes to the relative inefficiency of tile drainage systems in these soils. The ineffectiveness of the existing subsurface drainage system was demonstrated when we plugged it in three different areas of the station and observed little change in soil salinity and groundwater levels from year to year.

Attempts to address the low permeability and high salinity problems associated with the clay soils have included continuous flooding (ponding) for periods of days to weeks, intermittent flood irrigations, use of infiltration water amendments such as gypsum, Wetsol, Spersal and combinations thereof and installation of more aggressive (narrowly spaced) subsurface drainage systems. While each approach may be recommended in particular settings, each has had limited success and none has successfully eliminated the salinity problems of the clay soils.

The DREC lands are entirely underlain by a fine-sand saline aquifer with a flow gradient toward the Salton Sea that maintains high soil salinity and moisture levels in the clay at depths of 3 to 5 feet. When Donnan and Blaney (1954) conducted their original leaching studies, they noted the presence of this aquifer beneath the "Meloland Field Station" (as the DREC was called then, and still is by local residents). They found that the drainage system continued to remove considerably more salt than was initially available in the soil profile, so that leaching failed to provide a simple mass balance of salts. More recent measurements by our group show that the shallow aquifer is the source of these excess salts.

The conventional subsurface drainage systems (tiles) have been largely ineffective in controlling the salinity problems associated with this shallow artesian aquifer. In an effort to remedy this situation, we have installed a shal- 


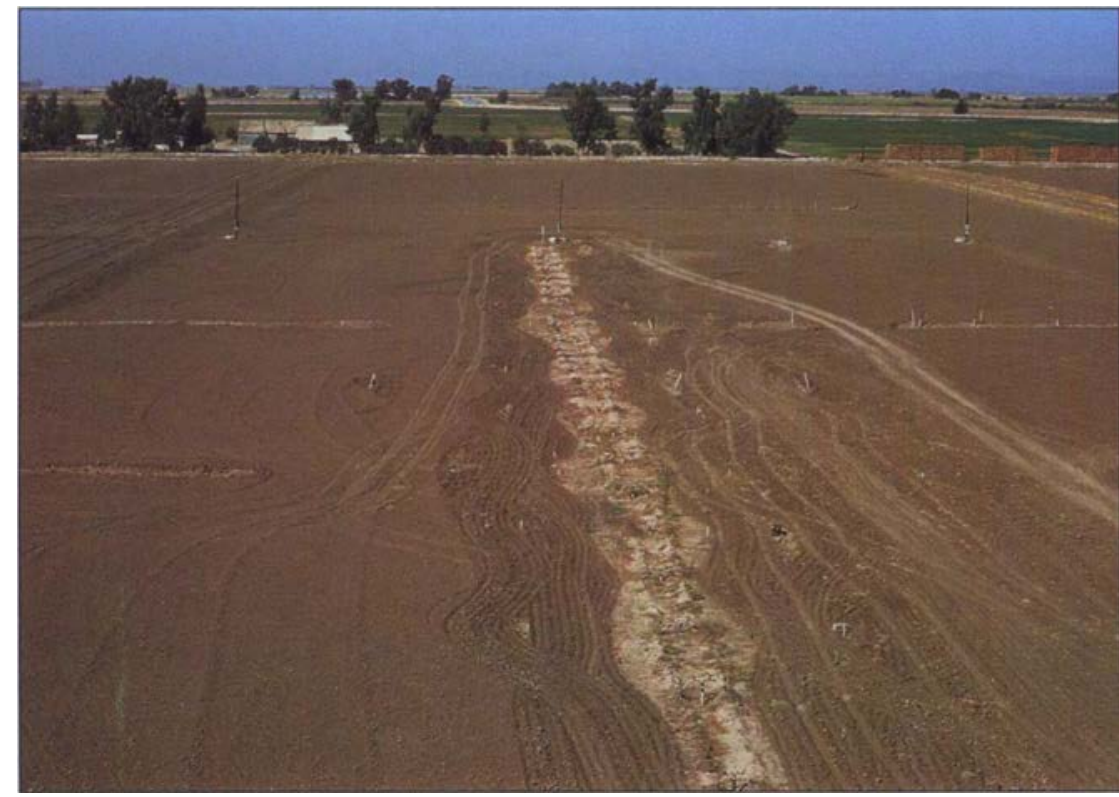

In an effort to control salinity associated with a shallow artesian aquifer, a shallow "skimming" drainage well system was installed.

low "skimming" drainage well system in the clay soils of Area 70 of the station. This system can maintain the artesian water levels at 6 to 8 feet below the land surface, or about 3 feet below the static artesian water level and 1 to 2 feet below the existing drainage laterals. We hypothesize that control of the artesian aquifer water levels will improve leaching and result in decreased soil salinities and increased crop yields. This paper summarizes some of our observations during the past 3 years.

The objective of this work was to determine if control of the artesian water levels to depths well below the existing drainage system in the fine sand would be effective in reducing soil salinity in the root zone under irrigated and ponded surface conditions. We investigated the effects of regular cropping and irrigation on soil salinity for approximately 3 years before initiating a 1-month ponded leaching experiment in August 1996. This paper focuses on the effects of both regular irrigation and ponding treatments on soil salinity in the top 4 feet of the soil.

\section{Experimental methods}

The field work was conducted in Area 70 of the DREC, a field comprised of Imperial clay soils with 50 to
$70 \%$ montmorrilonitic clay contents and soil salinities ranging from 7 to 14 $\mathrm{dS} / \mathrm{m}$ in the top 6 feet of soil. The clay is underlain by a fine sand that reaches depths of 30 feet or more and contains water at a pressure head equivalent to a depth of approximately 5 feet. A "skimming" drainage well system was installed in 1992, outfitted with a single pumping manifold and made operational in May 1993.

The system consists of 26 2-inch-diameter wells spaced 20 feet apart in a line along the border of the field (fig. 1).

Each well draws water from a depth of 12 to 20 feet and discharges it via a manifold connected to a diaphragm pump to a surface drainage canal at the head end of the field.

Using the middle nine wells of the skimming well system, we ran the pump continuously from May 1993 to May 1996 (with the exception of halfday maintenance periods roughly once a month). Bor-



Fig. 2. Average soil salinity at two soil-depth intervals during 3-year leaching experiment. der checks were placed around two areas, each 65 feet wide by 1,250 feet long, on either side of the skimming well system. The bordered areas were disked, cropped and irrigated under normal cultural practices during the pumping period. We monitored onflow rates, surface wetting-front advance rates, and changes in soil water content before and after irrigation for each irrigation event. Soil salinity, drainage water salinity and sand aquifer water levels were monitored weekly throughout the period to assess changes resulting from deeper control of the water table.

When the soil salinity of the area failed to improve, we planned a ponded leaching experiment, which 


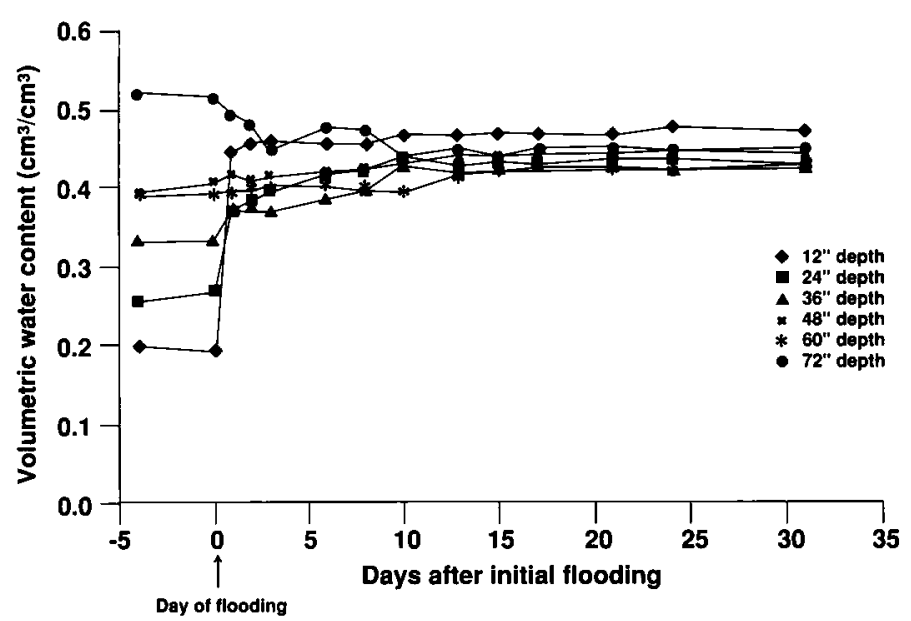

Fig. 3. Changes in average water content within the ponded area before and after flooding.

was initiated in August 1996. The field was disked again and border checks were placed around an area 62 feet wide by 128 feet long to hold water during continuous ponding. The pump was rehabilitated during June and July 1996 in preparation for its operation during the month of August. The ponded area was located east of and adjacent to the nine-well center of the skimming well system. Groundwater level, soil water content and soil salinity were monitored regularly before, during and after the ponding experiment, both inside and outside the flooded area. A transect of five monitoring sites was established, with an observation well, neutron probe (NP) access tube and soil salinity sampling location at each site (fig. 1). Soil salinity was measured directly via saturation extracts.

The area was flooded on Aug. 14 and the water level maintained until Sept. 19 by periodic refilling to the original level. Ponding water levels

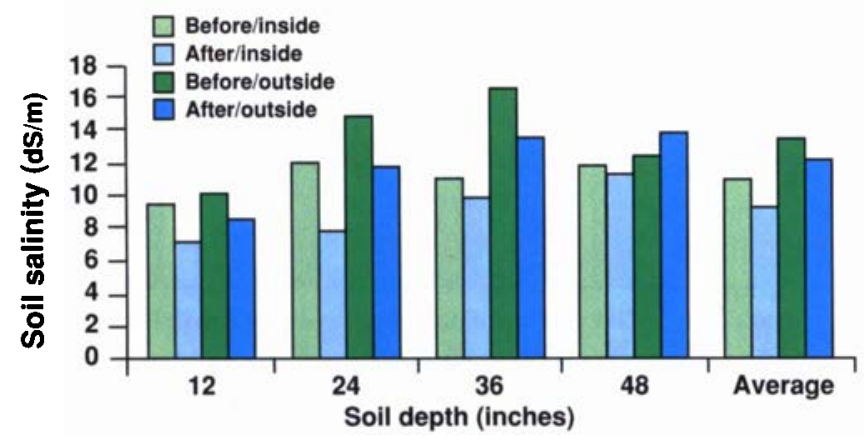

Fig. 5. Changes in soil salinity with depth inside and outside the ponded area before and after flooding.

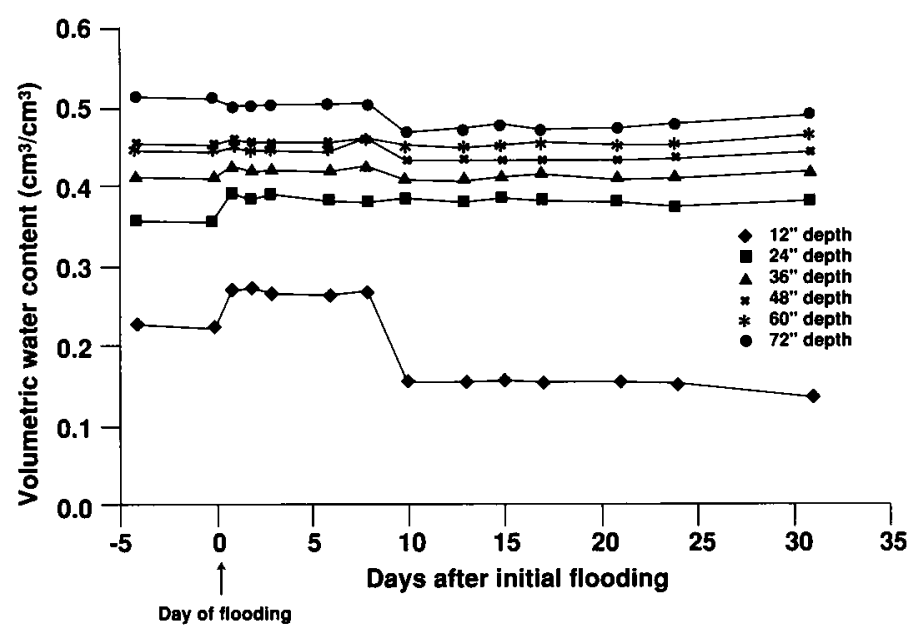

Fig. 4. Changes in average water content outside the ponded area before and after flooding. were measured using simple staff gauges located throughout the pond. The staff gauges were also used to estimate infiltration rates during ponding for comparison with independent measurements using standard ring infiltrometers initiated after the first week of flooding. The skimming well system was operated continuously throughout the ponding experiment, and drainage flow rates and salinity were monitored at 1- to 4-day intervals.

\section{Little change in salinity}

After 3 years of continuous cropping and control of the shallow aquifer-water levels, we found very little change in soil salinity near the soil surface (fig. 2), despite measurements of lower soil water contents at depths of 4 to 7 feet and maintenance of deeper groundwater levels throughout this period. Soil salinity at depths of approximately 2 feet improved slightly by the end of the study period, but not significantly so. At first, these results were somewhat surprising, if not disappointing; however, they are consistent with the extremely small permeabilities of the clay soils. Pumping flow rates from the drainage well system averaged roughly $40 \mathrm{~L} / \mathrm{min}$ during the 3-year period as compared to the 7 to $9 \mathrm{~L} /$ min flow rate obtained from the drainage laterals draining an area roughly twice as large prior to installation of the skimming well system. Drainage well-water salinity decreased slightly during the period, beginning at approximately $13 \mathrm{dS} / \mathrm{m}$ and declining to slightly less than $11 \mathrm{dS} / \mathrm{m}$ after the 3 years. These results led us to conduct the second leaching experiment involving continuous ponding.

\section{Continuous ponding}

In the continuous ponding experiment, we measured steady infiltration rates of approximately $0.1 \mathrm{in} / \mathrm{hr}$ from both the staff gauges in the ponded area and the ring infiltrometers. This value is very close to the independently measured hydraulic conductivity of the clay. Inside the ponded area, soil water contents increased at all but the 6-foot depth over the first 10 days of continuous ponding and then stabilized. We noted, however, that 2 weeks were required for the soil water content to approach saturated values at the 2- and 3-foot depths (fig. 3). Soil water contents at the 5- and 6-foot depths decreased slowly as a result of lowering the water levels of the shallow aquifer. The average soil water content outside the ponded area remained practically constant at the 3-, 4- and 5-foot depths, increased and then decreased after 1 week of flooding at the 1- and 2-foot depths, and decreased at the 6-foot depth (fig. 4). The 
decrease in soil water content at the 6foot depth suggests that the range of influence of the skimming well system extended beyond the flooded area. Lack of change in soil water contents at the midrange depths both inside and outside the ponded area suggests that control of the groundwater levels has limited influence on the top 3 feet of the soil profile. However, reducing soil water content at the 4- to 7-foot depths will help increase rates of soil water movement in the profile and improve leaching efficiency and salt removal.

Figure 5 summarizes the changes in soil-water salinity before and after the ponded leaching experiment at locations within and outside the ponded area. At all locations, soil salinity tended to increase with depth both before and after flooding. In the top 2 feet, however, soil salinity was substantially lower after the ponded period than before, while at the 3 - and 4-foot depths the salinity remained roughly the same (inside the ponded area) or increased (outside the ponded area). The average salinity for the 4foot soil profile as a whole decreased by $19.1 \%$ within the ponded area and by $12.5 \%$ outside the ponded area.

This overall improvement in soil salinity suggests that the 1-month period of ponding was sufficient to translocate some of the soil salt mass to a greater depth and perhaps into the shallow sand aquifer. Indeed, we found a slight though significant increase in

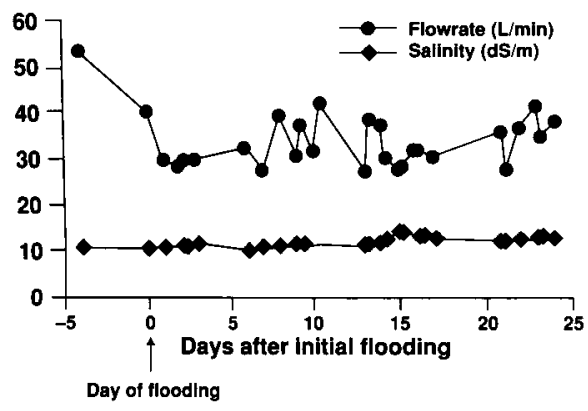

Fig. 6. Flow rate and salinity of the drainage well system during 1-month ponded leaching experiment.



drain-water salinity after about 14 days of continuous ponding, when water contents at all soil depths approached a constant value (fig. 6). No such changes in soil salinity were observed during the 3-year irrigated experiment (though there was an overall slight decrease in drain-water salinity) nor during the previous decades of measurements prior to installation of the skimming well system.

We continue to study drainage, soil salinity and associated irrigation issues for clay soils in the Imperial Valley to better understand leaching processes and to develop management practices that improve soil moisture and salinity conditions for these heavy, cracking soils. Our results thus far suggest that traditional subsurfacedrainage systems have limited value for controlling soil water content and salinity in the root zone in clay soils underlain by artesian aquifers (and may have little value in other soils as well). A shallow drainage-well system was effective in reducing soil water contents at all times and was useful in leaching reclamation of the clay soils only after continuous surface ponding and groundwater pumping.

M.E. Grismer is Professor, Department of Land, Air and Water Resources, UC Davis; and K.M. Bali is Farm Advisor, UC Desert Research $\mathcal{E}$ Extension Center, Holtville.

\section{References:}

Donnan WW, Blaney, HF. 1954. Drainage investigation in the Imperial Valley, CA; 1941-1951 (A 10-year summary). USDA Report No. SCS-TP-120. 